\title{
Visual Determination of Transformer Oil Quality Parameters
}

\author{
Kozlov V.K., Valiullina D.M., Kurakina O.E. \\ Kazan State Power Engineering University, \\ Kazan, Russian Federation
}

\begin{abstract}
During operation of the transformer, the oil in it undergoes profound changes usually referred to as aging. The electrical insulating properties of it deteriorate, and sediments accumulate on the active part, which makes it difficult to remove heat. Inhomogeneous solid formations can induce not only the voltage breakdown, but also impair the parameters such as viscosity and other characteristics of the oil, which are important for the reliable operation of the power transformers. Aromatic groups initially is present in the transformer oil composition during the operation of the oil, and because of the aging processes, the concentration of the unsaturated cyclic compounds increases. The aim of this work is to develop a new method for the determination of the aromatic compounds and colloidal particles. This goal is achieved using a visual inspection of the transformer oil samples in the visible range. The most significant result of the paper is the establishment of a correlation between the acid number of the transformer oil $(\mathrm{KOH})$, the tangent of the dielectric loss angle and the type of oil image under the visible light illumination. The significance of the obtained results lies in the fact that the presented method based on the analysis of the scattered and transmitted radiation, makes it possible to determine the presence of the aromatic compounds and colloidal particles in the transformer oil, as well as to define their concentration and size. This method simplifies the analysis of the transformer oil quality, and reduces the cost of the research, which is an important factor for the electric power industry.
\end{abstract}

Keywords: insulating oil, visual method, aromatic compounds, and colloidal particles.

\author{
DOI: https://doi.org/10.52254/1857-0070.2021.2-50.03 \\ UDC: 621.315.615.22
}

\section{Determinarea vizuală a parametrilor de calitate ai uleiului de transformator Kozlov V.K., Valiullina D.M., Kurakina O.E. \\ Universitatea energetică de Stat din Kazani, \\ Kazani, Federația Rusă}

Rezumat. În timpul funcționării transformatorului, uleiul din acesta suferă modificări profunde, care sunt de obicei numite îmbătrânire. Odată cu îmbătrânirea, apar modificări ale parametrilor chimici și electrofizici care caracterizează performanța uleiului. Proprietățile sale de izolare electrică se deteriorează, sedimentul se acumulează pe partea activă, ceea ce face dificilă îndepărtarea căldurii, accelerează îmbătrânirea izolației celulozice și agravează proprietățile sale de izolare electrică. Structurile solide neomogene pot agrava în mod semnificativ nu numai valoarea tensiunii de avarie, ci și un astfel de parametru, precum vâscozitatea și alte caracteristici ale uleiului, care sunt importante pentru funcționarea fiabilă a transformatoarelor de putere. Datorită proceselor fizice și chimice care apar sub influența temperaturii, a câmpului electric și a circulației uleiului în timpul exploatării uleiului de transformator, compoziția structurilor neomogene se modifică. Scopul acestei lucrări este de a dezvolta o nouă metodă pentru determinarea compuşilor aromatici şi a particulelor coloidale. Acest obiectiv este atins prin examinarea vizuală a probelor de ulei de transformator în intervalul vizibil. Cel mai semnificativ rezultat al articolului este stabilirea unei corelații între numărul acid al uleiului de transformator $(\mathrm{KOH})$, tangenta unghiului de pierderie în dielectric tan $\delta$ și tipul imaginii uleiului sub iluminarea luminii vizibile. Semnificația rezultatelor obținute este că metoda prezentată, bazată pe analiza radiației dispersate şi după parcurgere, face posibilă determinarea prezenței compușilor aromatici şi a particulelor coloidale în uleiul de transformatore, precum şi determinarea concentraţiei şi dimensiunii acestora. Această metodă simplifică analiza calităţii uleiului de transformator și, de asemenea, reduce costul cercetării, care este un factor important pentru industria energiei electrice.

Cuvinte-cheie: ulei izolant, metodă vizuală, compuși aromatici, particule coloidale.

(C) Kozlov V.K., Valiullina D.M., Kurakina O.E., 2021 


\title{
Визуальное определение параметров качества трансформаторного масла \\ Козлов В.К., Валиуллина Д.М., Куракина О.Е. \\ ФГБОУ ВО Казанский государственный энергетический университет, Казань, Российская федерация
}

\begin{abstract}
Аннотация. В процессе эксплуатации трансформатора масло в нем претерпевает глубокие изменения, которые обычно называют старением. При старении происходят изменения химических и электрофизических показателей, которые характеризуют работоспособность масла. Ухудшаются его электроизоляционные свойства, происходит накопление осадка на активной части, что затрудняет отвод тепла, ускоряет старение целлюлозной изоляции и ухудшает ее электроизоляционные свойства. Неоднородные твердые структуры, могут значительно ухудшить не только величину напряжения пробоя, но и такой параметр как вязкость и другие характеристики масла, важные для надежной работы силовых трансформаторов. Вследствие физических и химических процессов, протекающих под воздействием температуры, электрического поля и циркуляции масла при эксплуатации трансформаторного масла, состав неоднородных структур изменяется. Ароматические группы изначально присутствующие в составе трансформаторного масла в ходе эксплуатации масла, вследствие процессов старения, возрастает концентрация ненасыщенных циклических соединений. Это может происходить как в результате обменных процессов с изоляционными материалами, так и в результате химических процессов ароматизации, т.е. циклизации и дегидрирования алканов. Целью работы является разработка нового метода определения ароматических соединений и коллоидных частиц. Поставленная цель достигается за счет исследования образцов трансформаторного масла в видимом диапазоне визуальным способом. Наиболее существенным результатом статьи является установление корреляции между кислотным числом трансформаторного масла (КОН), тангенсом угла диэлектрических потерь tg $\delta$ и видом изображения масла при освещении видимым светом. Значимость полученных результатов состоит в том, что представленный метод, основанный на анализе рассеянного и прошедшего излучения, позволяет определять наличие в трансформаторном масле ароматических соединений и коллоидных частиц, а также определять их концентрации и размер. Данный метод упрощает анализ качества трансформаторного масла, а также снижает стоимость исследования, что является важным фактором для электроэнергетики.
\end{abstract}

Ключевые слова: изоляционное масло, визуальный способ, ароматические соединения, коллоидные частицы.

\section{ВВЕДЕНИЕ}

Старение трансформаторного масла (ТМ) оказывает значительное влияние на сроки и условия эксплуатации маслонаполненного оборудования в электроэнергетических системах [1-7]. В мировой практике существует множество способов для определения параметров качества ТМ и его старения [8-10]. На сегодняшний день общепризнанным механизмом старения ТМ является окислительный механизм [11] образования перекисей, окислов, продуктов глубокого окисления, формирование твердых частиц, которые достигнув некоторых размеров, выпадают в осадок [12]. Причем способность к окислению возрастает в ряду ароматические соединения, парафиновые соединения, нафтеновые соединения $[1,13]$.

Недавно нами было доказано существование еще одного механизма старения ТМ: в ходе его эксплуатации увеличивается доля ароматических групп, затем молекулы с такими же группами, как и в большинстве жидких нефтепродуктов самоорганизуются в надмолекулярные структуры за счет межмолекулярных взаимодействий электронов ароматических колец, укрупняются, уплотняются и выпадают в осадок. Отрицательное влияние примесей и коллоидных частиц на пробивную прочность трансформаторного масла показана в работах $[14,15]$.

В работе авторов, вышедшей в этом году, показано как меняется вклад люминесценции в рассеянное излучение при изменении концентрации ароматических соединений в масле (разные марки масел и разная степень старения) и изменение объема люминесцирующих молекул и цвета люминесценции при повышении концентрации ароматических соединений и их изменении (усложнении молекулярного состава этих соединений).

В случае дисперсных систем, в которых частицы не поглощают свет, не окрашены и имеют сферическую форму, не проводят электрический ток и их размеры малы по сравнению с $\lambda$ подающего света (не более $0,1 \lambda)$ и удалены друг от друга на достаточно 
большое расстояние, интенсивность света рассеянного под прямым углом описывается уравнением Релея прямо пропорциональна концентрации частиц в единице объема, квадрату объема частиц и обратно пропорциональна длине волны в четвертой степени. С увеличением размера частиц зависимость интенсивности рассеянного света от длины волны становится менее резкой, показатель степени $\lambda$ в уравнении снижается от 4 до 2 . В системах, где размер частиц становится несколько больше длины волны (показатель достигает 2), рассеянный свет становится белым. Когда же размер частиц значительно превышает $\lambda$ (показатель равен 0), светорассеяние переходит в отражение света, не зависящее от $\lambda$. В тех случаях, когда не выполнены условия интенсивного рассеяния, в частности для дисперсных систем с частицами, поглощающими свет, значение показателя может быть значительно больше 4. Например, поглощая фиолетово-синюю часть (400-480 нм) видимого света, коллоидная система оказывается окрашенной в цвет, дополнительный поглощенному - желтый при поглощении голубовато-зеленой части (480510 нм) она принимает красноватую окраску. Трансформаторное масло при сильном старении имеет красно-коричневый оттенок, что говорит о поглощении света при $\lambda<700$ нм. Следует отметить, что молекулярное рассеяние света, всегда присутствующее в жидкостях, существенно слабее рассеяния на коллоидных структурах (интенсивность рассеянного света составляет около $10-6 \div 10-7$ часть от интенсивности падающего света) и его практически невозможно наблюдать на фоне Релеевского рассеяния частицами.

Основными параметрами, характеризующими степень старения ТМ являются кислотное число (КОН) трансформаторного масла и тангенс угла диэлектрических потерь $\operatorname{tg} \delta \quad[2,16,17]$. Кислотное число ТМ определяют по ГОСТ 5985-79 [18] титрованием кислых соединений испытуемого продукта спиртовым раствором гидроокиси калия в присутствии цветного индикатора и определении для масел кислотного числа, выраженного в мг КОН/г.

При этом определяют сумму всех окисленных продуктов в том числе и находящихся в коллоидных частицах, так как в процессе определения КОН, анализируемый раствор кипятят с обратным холодильником в течении 5 мин при постоянном перемешивании, что приводит к разрушению частиц.

Тангенс угла диэлектрических потерь ТМ при частоте 50 Гц, как показано в [1] и многих других последующих работах, обусловлен только электрофоретической проводимостью коллоидных частиц и микроэмульсий.

Вопросам старения и оценки качества ТМ посвящено огромное количество работ наших соотечественников и зарубежных коллег. Например, в работе [19] представлен метод, используемый для определения показателя цвета ТМ.

В статье [20] представлен обзор большинства методов, используемых для диагностики неисправностей и оценки изоляционного масла для трансформаторов с помощью анализа растворенных газов DGA. A в [21] обсуждается несколько практикующихся методов оценки свойств ТМ для поддержания качественной работы трансформатора.

Проблема определения коллоидных частиц и примесей в ТМ также является актуальной для электроэнергетики.

В работе [22] определение типа и размеров частиц в трансформаторном масле осуществляется с помощью метода оптимизации роя частиц. В Российской Федерации примеси определяются согласно ГОСТ 6370-83 [23].

Сущность данного метода определения содержания механических примесей в нефтепродуктах заключается в определении массы механических примесей задерживаемых мембранными фильтрами при фильтровании через них испытуемого нефтепродукта.

В литературе мы не обнаружили упоминаний о применении визуального метода для определения ароматических соединений и коллоидных частиц в ТМ.

Метод, представленный в нашей работе, отличается простотой проведения исследования, дешевизной необходимого оборудования, при сохранении точности получаемых результатов.

В своей работе, на примере нескольких образцов, мы рассмотрели, как меняется рассеянное и прошедшее излучение и его цвет в зависимости от характеристик ТМ. 


\section{МЕТОДЫ, РЕЗУЛЬТАТЫ И ОБСУЖДЕНИЕ}

Таким образом, цвет излучения, прошедшего сквозь состаренное трансформаторное масло, определяется рассеянием излучения на коллоидных структурах, тогда как цвет свежего и слабо состаренного трансформаторного масла зависит от содержания в масле ароматической фракции сечение поглощения которой существенно больше сечения рассеяния на коллоидных частицах. Поэтому люминесценция ароматических соединений будет интенсивнее даже при существенно меньших концентрациях, нежели Релеевское рассеяние на коллоидных частицах. В условиях реальной эксплуатации многие процессы старения идут одновременно и

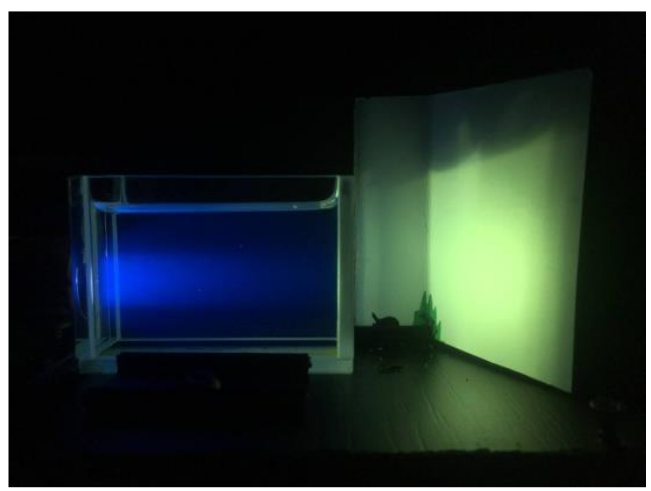

a)

Рис. 1. Фотография стандартного образца массовой доли примесей: а - массовая доля примесей $0,005 \%$; б - массовая доля примесей $0,015 \%$.

Fig. 1. Photo of a standard sample of the mass fraction of impurities: a - mass fraction of impurities $0.005 \%$; $b$ - mass fraction of impurities $0.015 \%$.

Как видно из рис. 1a, образец окрашен в синий цвет за счет более сильного рассеяния коротковолнового излучения, согласно закону Релея. Увеличение концентрации примеси приводит к усилению интенсивности рассеянного света (рис. 1б) без изменения его цвета. Наличие диффузного рассеяния света образцом приводит к размыванию изображения прошедшего пучка света на экране, расположенном за образцом.

На рис. 2 приведена фотография стандартного образца кислотного числа нефтепродуктов КЧ-0,02-НС с кислотным числом 0,02 мг КОН/г. Стандартный образец представляет собой толуольный раствор ароматической карбоновой кислоты в вазелиновом масле. Как следует из рис. 2 параллельно, поэтому рост кислотного числа трансформаторного масла, увеличение доли ароматической компоненты, а также коллоидных структур имеют высокую степень корреляции и повышаются в процессе старения трансформаторного масла.

Образцы трансформаторного масла облучались в прямоугольной емкости(кювете) белым светом светодиода с излучением накачки на длине волны 450 нм. На рис. 1 а приведена фотография Государственного стандартного образца массовой доли механических примесей ГСО МПН-0,005 с массовым процентом примесей $0,005 \%$, а на рис. 16 - образца ГСО МПН0,015 с массовым процентом примесей 0,015 $\%$.

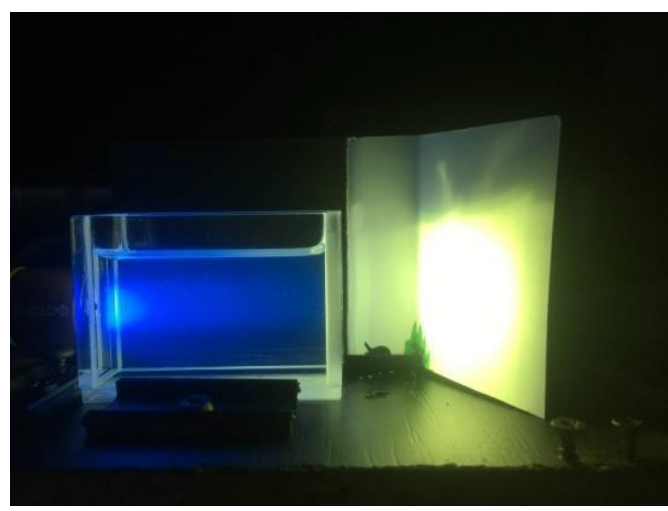

б)

отсутствие механических частиц в образце приводит к отсутствию рассеянного света.

Отсутствие же ароматических соединений в образцах $1 \mathrm{a}, 16$ и 2 приводит к отсутствию молекулярного поглощения в указанных образцах и как следствие к отсутствию люминесцентного свечения на начальном участке кюветы.

На рис. 3a приведена фотография трансформаторного масла с кислотным числом 0,02 мг КОН/Г и тангенсом угла диэлектрических потерь $\operatorname{tg} \delta=0,018$, пробивным напряжением $U_{n p}=67,1 \kappa B$, а на рис. 36 фотография трансформаторного масла с кислотным числом 0,1 мг КОН/г, $\operatorname{tg} \delta=0,098$ и $U_{n p}=90 \kappa B$. 


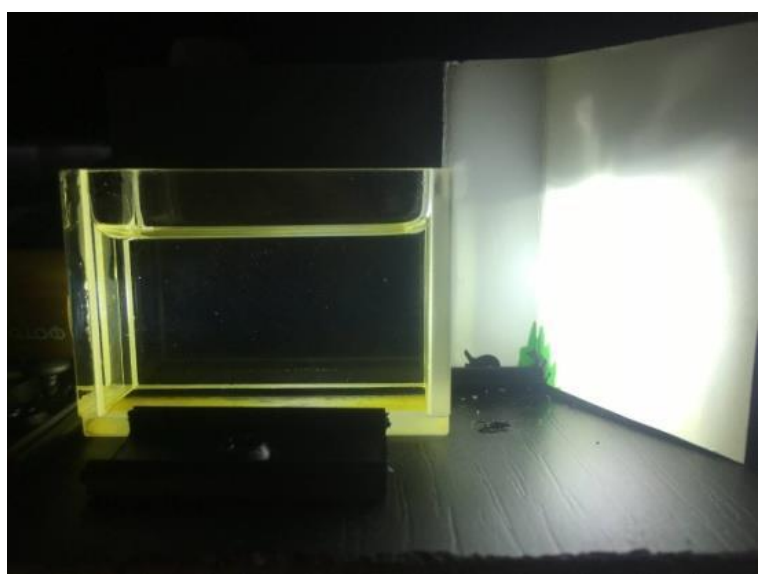

Рис. 2. Фотография стандартного образца кислотного числа нефтепродуктов КЧ-0,02-НС с кислотным числом 0,02 мг КОН/г.

Fig. 2. Photo of a standard sample of the acid number of petroleum products KCh-0.02-NS with an acid number of $0.02 \mathrm{mg} \mathrm{KOH} / \mathrm{g}$.

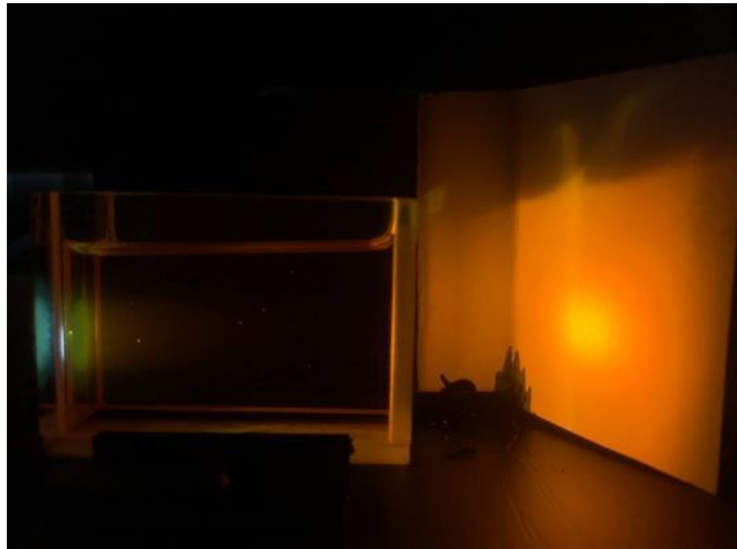

a)

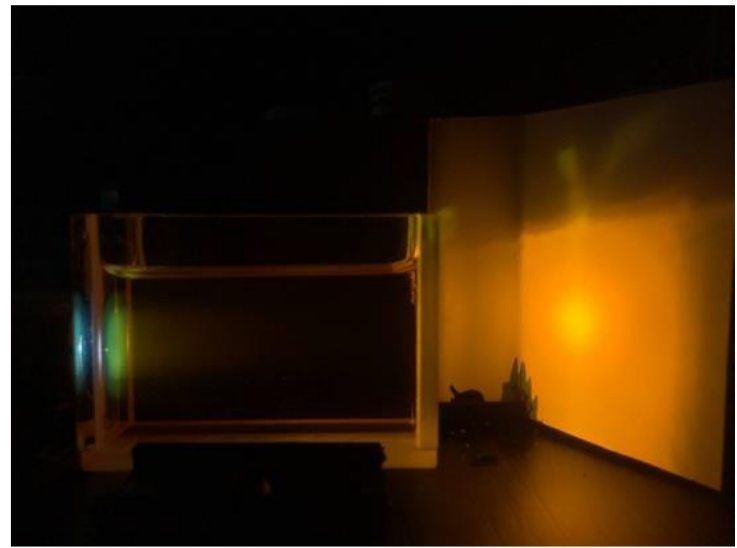

б)

Рис. 3. Фотография трансформаторного масла:

a - с кислотным числом 0,02 мг КОН/г, $\operatorname{tg} \delta=0,018$, пробивным напряжением $U_{n p}=67,1 \kappa B$; б - с кислотным числом 0,1 мг КОН/г, $\operatorname{tg} \delta=0,098$ и $U_{n p}=90 \kappa B$.

Fig. 3. Photo of transformer oil:

a - with an acid number of $0.02 \mathrm{mg} \mathrm{KOH} / \mathrm{g}, \operatorname{tg} \delta=0,018$ breakdown voltage $U_{n p}=67,1 \kappa B$; b - with an acid number of $0.1 \mathrm{mg} \mathrm{KOH} / \mathrm{g}, \operatorname{tg} \delta=0,098$ and $U_{n p}=90 \kappa B$.

Как видно на рис. 3 повышение кислотного числа масла и тангенса угла диэлектрических потерь приводит к изменению концентрации и структуры ароматических молекул. Если в случае масла рис. 3а, люминесценция слабая и имеет цвет зеленый, то в случае 36 люминесценция более яркая и цвет ее меняется на зеленоватожелтый, что свидетельствует о повышении числа бензольных колец в ароматических молекулах в процессе окисления. Появляется слабое светло-желтое рассеяние рис. 3а, которое усиливается и меняет цвет на желтый в случае 3б. Цвет рассеянного излучения аналогичен цвету прошедшего излучения (зарегистрирован на экране) цвет прошедшего излучения обусловлен молекулярным поглощением ароматических соединений в области 400-600 нм, а также рассеянием на коллоидных частицах в области 600-800 нм. Появление рассеяния в красной области свидетельствуют о появлении в образце масла (рис. 3б) частиц размеры которых сравнимы с длиной волны этого диапазона длин волн. Узкий спектральный диапазон (600-800 нм) и слабая 
зависимость интенсивности рассеяния от длины волны (размеры частиц сравнимы с длиной волны падающего света) приводят к тому, что прошедшее и рассеянное излучение имеет одинаковый цвет.

На рис. $4 \mathrm{a}$ приведена фотография трансформаторного масла с кислотным числом 0,08 мг $\mathrm{KOH}, \quad U_{n p}=41 \kappa B$, концентрацией $\mathrm{H}_{2} \mathrm{O} \mathrm{CH}_{2} \mathrm{O}=46,15 \mathrm{ppm}$, а на рис 46 фотография трансформаторного масла с кислотным числом 0,02 мг КОН, $U_{n p}=28,9 \kappa B$ и влагосодержанием 30,38 ppm.

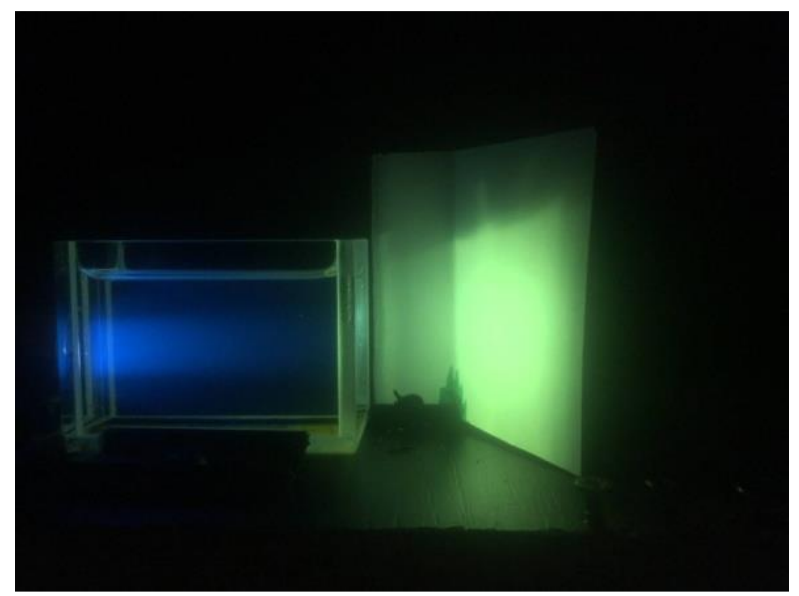

б)

a)

Рис. 4. Фотографии трансформаторного масла:

а - с кислотным числом 0,08 мг КОН, $U_{n p}=41 \kappa B$, концентрация $\mathrm{H}_{2} \mathrm{O}=46,15 \mathrm{ppm}$; б - с кислотным числом 0,02 мг КОН, $U_{n p}=28,9 \kappa B$ и концентрация $\mathrm{H}_{2} \mathrm{O}=30,38 \mathrm{ppm}$.

Fig. 4. Photos of transformer oil:

a - with an acid number of $0.08 \mathrm{mg} \mathrm{KOH}, U_{n p}=41 \kappa B, \mathrm{H}_{2} \mathrm{O}$ concentration $=46.15 \mathrm{ppm}$;

b - with an acid number of $0.02 \mathrm{mg} \mathrm{KOH}, U_{n p}=28,9 \kappa B$ and the concentration of $\mathrm{H}_{2} \mathrm{O}=30.38 \mathrm{ppm}$.

Как следует из рисунка 4 в обоих образцах проявляется достаточно сильное рассеянное излучение, обусловленное рассеянием на частицах в масле, но если в первом случае (рис. 4a) в масле имеется большая концентрация ароматических соединений (наличие сильной люминесценции цвет рассеяния желто-красный, то во втором (рис. 4б) ароматические соединения отсутствуют (нет люминесценции) цвет рассеянного излучения синий. В случае рис. 4 а рассеяние происходит на крупных коллоидных частицах (в том числе и частицах воды), а в случае рис. 46 рассеяние происходит на частицах, размер которых меньше 100 нм и эти частицы при таком кислотном числе могут быть только частицами воды и именно этим обусловлено низкое $U_{n p в}$ случае масла рис. 4б. В случае, если рассеянное излучение имеет цвет в области от фиолетового до красного, то размеры частиц будут соизмеримы с длиной волны этой области 400-800нм. Количество ароматических соединений в масле определяется

интенсивностью люминесценции наблюдаемой в начале кюветы, а их молекулярный состав определяется цветом этой люминесценции.

Авторы в предыдущей работе показали, что процесс осадкообразования в ТМ определяется главным образом не окисленными, а ароматическими соединениями, т.е. достигнув некоторой концентрации, арены группируются и выпадают в осадок. В работах авторов, было показано, что по элементному составу почти все исследуемые твердые частицы состаренного ТМ можно распределить на два типа: частицы, состоящие из углерода, водорода и кислорода - это примеры асфальтенов; частицы второго типа, содержащие лишь углерод и водород образованы из плотно-упакованных «пачек» ароматических колец, формирующихся в результате межмолекулярных взаимодействий, причем процесс старения главным образом обусловлен образованием частиц второго типа. Таким образом 
кислотное число ТM определяется окисленными молекулами и коллоидными частицами, состоящими из окисленных структур, а тангенс угла диэлектрических потерь обусловлен электрофоретической проводимостью, как коллоидных частиц, включающих окисленные молекулы, так и частиц, состоящих только из ароматических неокисленных молекул. Установленная авторами в предыдущих работах корреляционная зависимость между кислотным числом ТМ и тангенсом угла диэлектрических потерь при изменении кислотного числа до 0,1 мг КОН/г и $\operatorname{tg} \delta 90^{\circ} \mathrm{C}$ до $8 \%$ свидетельствует о том, что в области превышающей эти значения кислотного числа и $\operatorname{tg} \delta$ начинают изменятся процессы образования (скорости роста концентраций, рост размеров частиц) частиц первого и второго типов. В статье, вышедшей еще в 2010г. с участием одного из авторов показано, что при превышении кислотного числа ТМ 0,1 мг КОН/г, вследствие коагуляции, увеличиваются размеры частиц, начинают образовываться крупные частицы, что приводит к резкому снижению электрической прочности ТМ. С учетом процентного соотношения парафинов, нафтенов и ароматики в ТМ и способности их к окислению можно констатировать, что коллоидные частицы состоят в основном из окисленных молекул парафинов и нафтенов и как показано в статье авторов 2020 года эти соединения, а значит и частицы, состоящие из них не поглощают излучение в видимой области спектра, а значит они, с точки зрения рассеяния света удовлетворяют условию
Рэлея и будут рассеивать свет в видимой области спектра при соблюдении требований к размерам этих частиц. Частицы, состоящие из ароматических молекул, интенсивно поглощают видимое излучение и чем более старое ТМ тем в более широкой области спектра происходит поглощение света этими частицами. Таким образом частицы второго типа, образующиеся в ТМ, не удовлетворяют условиям Рэлея, и не принимают (из-за поглощения) участия в рассеянии света. Поэтому если рассматривать ТМ при облучении белым светом, то в рассеянном свете будет наблюдаться рассеянное излучение на частицах первого типа, интенсивность и цвет которого будут подчиняться закону Рэлея и этот эффект будет полностью коррелировать с кислотным числом ТМ и меняться при изменении КОН в процессе старения ТМ. Частицы второго типа будут существенно влиять на люминесценцию ТМ, которая отсутствует у молекул входящих в состав частиц первого типа. Интенсивность и цвет люминесценции ТМ будут коррелировать с тангенсом угла диэлектрических потерь $\operatorname{tg} \delta$. Интегральная интенсивность люминесценции будет увеличиваться с ростом $\operatorname{tg} \delta$, а цвет люминесценции будет смещаться от синей области в сторону красной области спектра с ростом $\operatorname{tg} \delta$.

На рис. 5 приведены фотографии ТМ облученного излучением светодиода $\lambda=395 \mu$, в этом случае нет рассеянного излучения и все, что видно на фотографии это люминесценция.

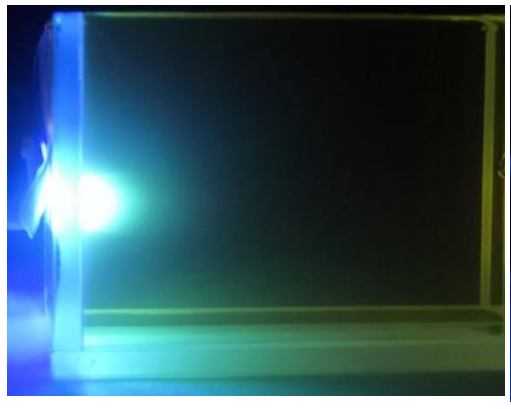

a)

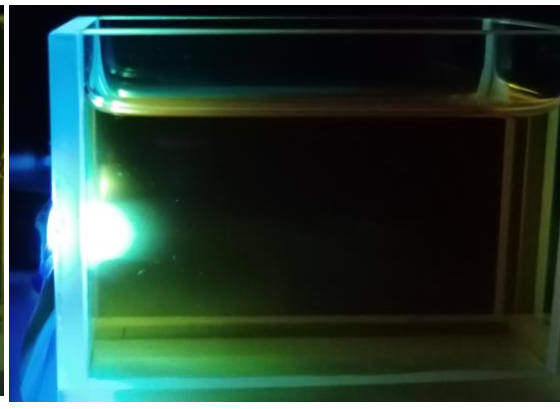

б)

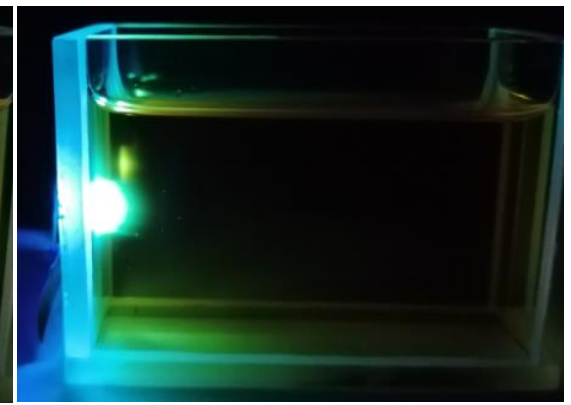

B)

Рис. 5. Фотография ТМ: $\operatorname{a}-\operatorname{tg} \delta=1,84 ; \sigma-\operatorname{tg} \delta=4,73$; в- $\operatorname{tg} \delta=8,5$, при возбуждении люминесценции излучением светодиода с $\lambda=395 \mu$

Fig. 5. Photo of TM: $\mathrm{a}-\operatorname{tg} \delta=1,84 ; \mathrm{b}-\operatorname{tg} \delta=4,73 ; \mathrm{c}-\operatorname{tg} \delta=8,5$, upon excitation of luminescence by the radiation of a LED with $\lambda=395 \mu$. 
Как следует из рис. 5 с увеличением $\operatorname{tg} \delta$ масла размер пятна люминесценции уменьшается за счет полного поглощения возбуждающего излучения в более тонком слое при увеличении люминесцирующих молекул. Цвет люминесценции меняется от синего, через сине-зеленый к зеленому.
Люминесценцию более длинных (с большим количеством бензольных колец), которые образуются при старении, можно наблюдать если увеличить длину волны возбуждающего излучения. На рис. 6 приведены фотографии тех же масел, что и на рис. 5, но при возбуждении люминесценции излучением зеленого лазера с $\lambda=550 н$.

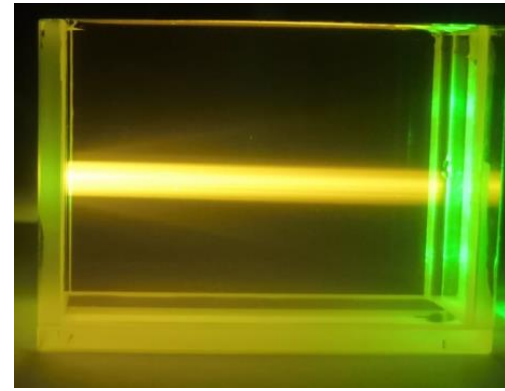

a)

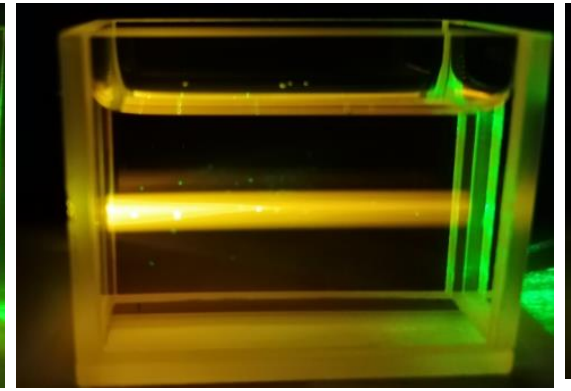

б)

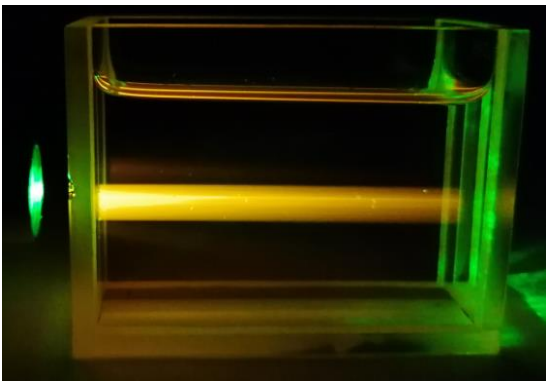

B)

Рис. 6. Фотография ТМ: $\operatorname{a}-\operatorname{tg} \delta=1,84 ;$ б- $\operatorname{tg} \delta=4,73 ;$ в- $\operatorname{tg} \delta=8,5$, при возбуждении люминесценции излучением зеленого лазера с $\lambda=550 \mu$

Fig. 6. Photo of TM: $\mathrm{a}-\operatorname{tg} \delta=1,84 ; \mathrm{b}-\operatorname{tg} \delta=4,73 ; \mathrm{c}-\operatorname{tg} \delta=8,5$, upon excitation of luminescence by radiation of a green laser with

При возбуждении зеленым лазером наблюдается желтая люминесценция, интенсивность которой возрастает с ростом $\operatorname{tg} \delta \mathrm{TM}$.
Общую картину с люминесценцией и рассеянным излучением можно наблюдать если освещать масло излучением светодиода белого цвета с накачкой на длине волны 450 нм, фотографии приведены на рис. 7.

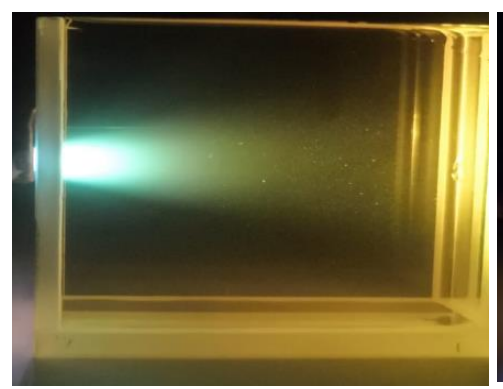

a)

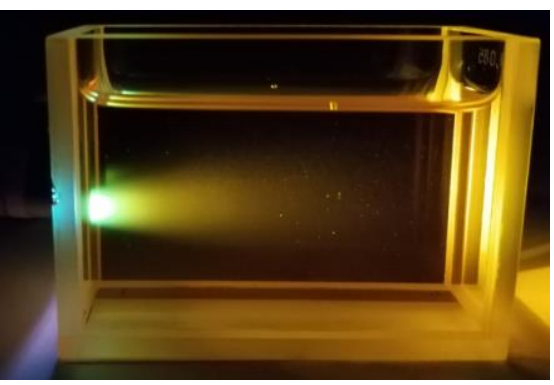

б)

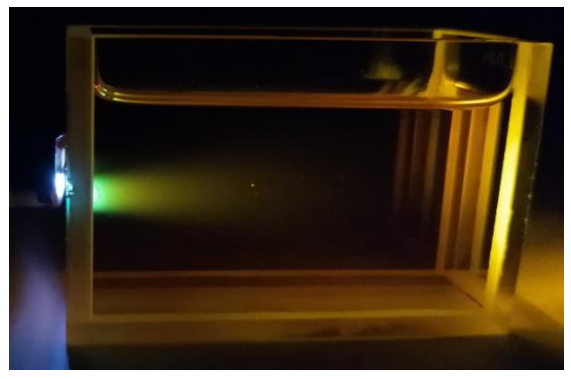

B)

Рис. 7. Фотография ТМ: $\mathrm{a}-\operatorname{tg} \delta=1,84$ и КОН=0,035; б- $\operatorname{tg} \delta=4,73$ и КОН=0,089; в $\operatorname{tg} \delta=8,5$ и КОН $=0,053$

Fig. 7. Photo of TM: $\mathrm{a}-\operatorname{tg} \delta=1,84$ and $\mathrm{KOH}=0.035 ; \mathrm{b}-\operatorname{tg} \delta=4,73$ and $\mathrm{KOH}=0.089$; $\mathrm{c}-\operatorname{tg} \delta=8,5$ and $\mathrm{KOH}=\mathbf{0 . 0 5 3}$

С ростом $\operatorname{tg} \delta$ в начале луча видно пятно люминесценции, параметры которого меняются, как описано выше с ростом $\operatorname{tg} \delta$.
На рис. 7 кроме люминесценции можно наблюдать рассеянное излучение, конус Тиндаля, причем интенсивность излучения возрастает при увеличении кислотного числа, 
а также с ростом кислотного числа меняется цвет рассеянного излучения, что свидетельствует о повышении концентрации рассеивающих частиц и их размеров, с ростом кислотного числа ТМ.

Таким образом, цвет масла однозначно коррелирует с показателями масла, такими как кислотное число и тангенс угла диэлектрических потерь, т.е. по цвету масла можно установить достигли ли эти показатели предельных значений и соответственно принимать решения о дальнейшем наблюдении трансформатора.

\section{ВЫВОДЫ}

В процессе проведенных исследований впервые были сделаны и сформулированы следующие выводы:

1. Анализ рассеянного и прошедшего излучения позволяет определять наличие в

\section{ЛИТЕРАТУРА (REFERENCES)}

[1] Lipshtein R.A., Shakhnovich M.I. Transformatornoe maslo [Transformer oil]. Moscow, 1983, 296 p. (In Russian).

[2] RD 34.45-51.300-97 Ob'em i normy ispytaniya energooborudovaniya [The scope and standards of testing electrical equipment], Moscow, 2001, 177 p. (In Russian).

[3] Wilson A.C.M., Insulating liquids: their uses, manufacture and properties, London, 1980, 221 p.

[4] Alshehawy A.M., Mansour D.A., Ghali M. Impact of thermal aging of transformer oil on UVVis optical spectrum and dielectric properties. Eighteenth International Middle East Power Systems Conference (MEPCON), 2016, pp. 860-865. doi: 10.1109/MEPCON.2016.7836996

[5] Ueta G., Tsuboi T., Okabe S.и Amimoto T. Study on degradation causing components of various characteristics of transformer insulating oil. IEEE Transactions on Dielectrics and Electrical Insulation, 2012, vol. 19, no. 6, pp. 2216-2224. doi: 10.1109/TDEI.2012.6396983.

[6] Hadjadj Y., Fofana I., Sabau J., Briosso E. Assessing Insulating Oil Degradation by Means of Turbidity and UV/VIS Spectrophotometry Measurements. IEEE Transactions on Dielectrics and Electric Insulation, 2015, vol. 22, no. 5, pp. 2653-2660. doi: 10.1109 / TDEI.2015.005111.

[7] Karmakar S., Meshram S., Kalathiripi H. Evaluation of Partial Discharge Aged Transformer Oil Using Optical Spectroscopy Techniques. International Conference on High Voltage Engineering and Technology (ICHVET), 2019, pp. 1-5, doi: 10.1109/ICHVET.2019.8724352. трансформаторном масле ароматических соединений и коллоидных частиц.

2. Данный метод позволяет определять концентрацию и размер коллоидных частиц в TM, появившихся в процессе эксплуатации.

3. Приведенные результаты, позволяют сделать утверждение, что такие параметры как кислотное число масла и тангенс угла диэлектрических потерь, могут быть определены простым визуальным способом, по рассеянному излучению от ТМ при освещении его белым светом.

4. Данный метод упрощает анализ качества трансформаторного масла, а также снижает стоимость исследования, так как для него не нужны никакие дополнительные приборы, кроме белого широко распространенного в быту светодиода и емкости для масла, что является важным фактором для электроэнергетики.

[8] Wada J., Ueta G., Okabe S., Amimoto T. Method to evaluate the degradation condition of transformer insulating oil - establishment of the evaluation method and application to field transformer oil. IEEE Transactions on Dielectrics and Electrical Insulation, 2015, vol. 22, no. 2, pp. 12661274. doi: 10.1109/TDEI.2015.7076830.

[9] Heydon R. G., Gronowski B., Rungis J., Diesendorf J., Mitchell F. Condition monitoring of transformer oil. International Conference on Power Electronic Drives and Energy Systems for Industrial Growth, 1998, vol.1, pp. 249-253. doi: 10.1109/PEDES.1998.1330022.

[10]Degeratu S., Rotaru P., Rizescu S. Condition monitoring of transformer oil using thermal analysis and other techniques. J Therm Anal Calorim, 2015, vol. 119, pp. 1679-1692. doi:10.1007/s10973-014-4276-3

[11] Wicaksono B., Kong H., Markova L.V., Han H.G. Application of fluorescence emission ratio technique for transformer oil monitoring. Journal of the International Measurement Confederation, 2013, vol. 46, Issue 10, pp. 4161-4165. doi: 10.1016/j.measurement.2013.07.033.

[12]Loiselle L., Rao U. M., Fofana I., Jaya T. Monitoring colloidal and dissolved decay particles in ester dielectric fluids. IEEE Transactions on Dielectrics and Electrical Insulation, 2020, vol. 27, no. 5, pp. 1516-1524. doi: 10.1109/TDEI.2020.008719.

[13] Georgiev A., Karamancheva I., Topalova L. Determination of oxidation products in transformer oils using FT-IR spectroscopy. Journal of Molecular Structure, 2008, vol. 872, Issue 1, pp.18-23. doi:10.1016/j.molstruc.2007.02.014. 
[14] Miners K. Particles and Moisture Effect on Dielectric Strength of Transformer Oil Using VDE Electrodes. IEEE Transactions on Power Apparatus and Systems, vol. PAS-101, 1982, no. 3, pp. 751-756, doi: 10.1109/TPAS.1982.317291.

[15] Sheshakamal J., Cross J. D. The influence of impurities on electrohydrodynamic motion in insulating oils. Conference on Electrical Insulation and Dielectric Phenomena, 1989, pp. 338-345. doi: 10.1109/CEIDP.1989.69569.

[16] Karthik R., Sree Renga Raja T. Investigations of transformer oil characteristics. IEEJ Trans Elec Electron Eng, 2012 vol.7, pp. 369-374. doi: 10.1002/tee.21742

[17]Peng D., Yang D., Wang C., Li M., Research of the Dielectric Loss factor tan delta of Transformer Oil by Multi-Parameter Regression Analysis. Asia-Pacific Power and Energy Engineering Conference, 2009, pp. 1-3, doi: 10.1109/APPEEC.2009.4918669.

[18]GOST 5985-79. Nefteprodukty. Metod opredeleniya kislotnosti i kislotnogo chisla [State Standard 5985-79. Method of measurement. Measurement of flow rate and volume of liquids and gases by means of orifice devices Petroleum

\section{Сведения об авторах.}
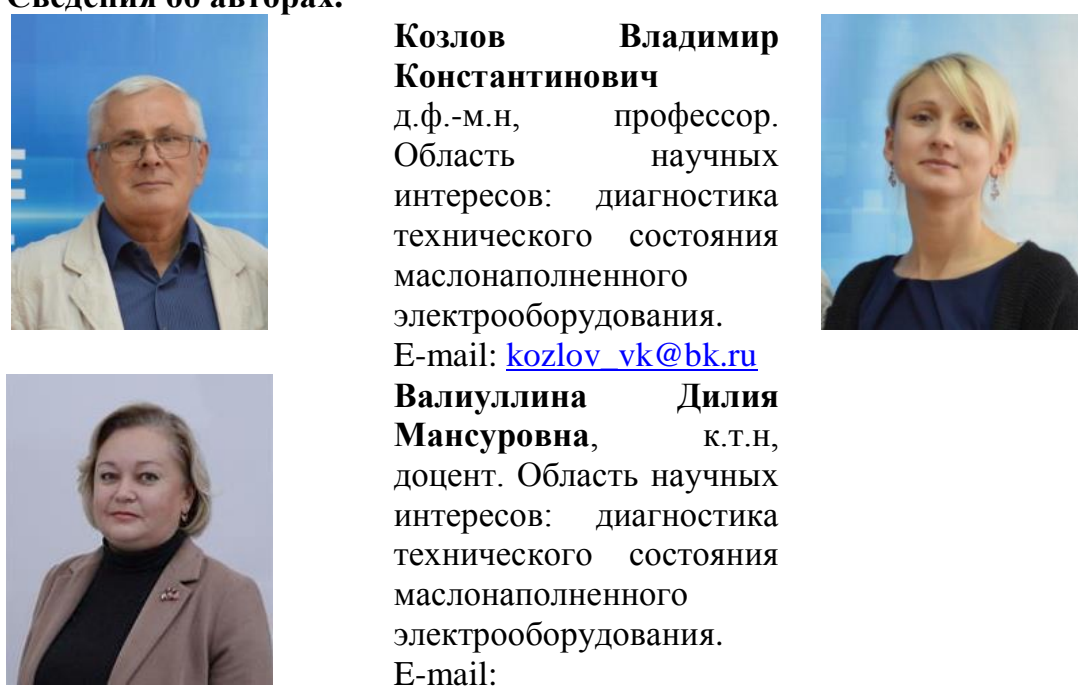

E-mail: kozlov_vk@bk.ru

Валиуллина Дилия

Мансуровна, к.т.н, доцент. Область научных интересов: диагностика технического состояния маслонаполненного электрооборудования. E-mail: valiullinadiliya@mail.ru products. Method for determination of acidity and acid number]. Moscow, Standartinform Publ., 2009. 9 p.

[19]Leong Y.S.; Ker P.J.; Jamaludin M.Z.; M. Nomanbhay S.; Ismail A.; Abdullah F.; Looe H.M.; Lo C.K. UV-Vis Spectroscopy: A New Approach for Assessing the Color Index of Transformer Insulating Oil. Sensors, 2018, no. 18(7), pp. 2175. doi:10.3390/s18072175

[20] Taneja M. S., Pandey K., Sehrawat S. A review on prognosis and diagnosis of transformer oil quality using intelligent techniques based on dissolved gas analysis. 7th India International Conference on Power Electronics (IICPE), 2016, pp. 1-6, doi: 10.1109/IICPE.2016.8079419.

[21] Mahanta D. K., Andrew O. Transformer Dielectric Liquid: A Review. IEEE PES/IAS PowerAfrica, 2020, pp. 1-5, doi: 10.1109/PowerAfrica49420

[22] GOST 6370-2018 Neft', nefteprodukty i prisadki Metod opredeleniya mekhanicheskikh primesei [State Standard 6370-2018. Petroleum, petroleum products and additives. Method for determination mechanical admixtures]. Moscow, Standartinform Publ., 2009. 6 p.

\author{
Куракина Ольга \\ Евгеньевна, к.т.н, \\ доцент. Область научных \\ интересов: диагностика \\ технического состояния \\ маслонаполненного \\ электрооборудования. \\ E-mail: \\ random_ji@mail.ru
}

